\title{
Voluntary Stopping of Eating and Drinking in Swiss Outpatient Care
}

\author{
Sabrina Stängle $e^{1,2}$, Wilfried Schnepp ${ }^{1}$, Daniel Büche ${ }^{3}$, and André Fringer ${ }^{1,2}$ \\ ${ }^{1}$ Department of Nursing Science, Faculty of Health, Witten/Herdecke University, Witten, Germany \\ ${ }^{2}$ Institute of Nursing, ZHAW School of Health Professions, Winterthur, Switzerland \\ ${ }^{3}$ Palliative Centre St. Gallen, Cantonal Hospital St. Gallen, St. Gallen, Switzerland
}

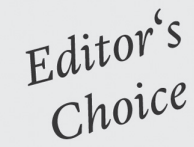

\begin{abstract}
Besides physician-assisted suicide, there is another end-of-life practice under discussion: voluntary stopping of eating and drinking (VSED). In this study, we assess the occurrence of VSED in outpatient care and evaluate nurses' attitudes about it. We recruited 395 nurses (24\% response rate) in our online survey. The occurrence of VSED in Switzerland lies at 0.5\%. Most nurses (84.6\%) were aware of VSED, and $39.5 \%$ had experienced it with patients. VSED was mostly (70.3\%) regarded as a natural death, and nearly all (95.1\%) were willing to care for these patients; however, about one-quarter (26.5\%) expressed moral concerns. Our results show that VSED occurs in rare cases, and that nurses are willing to accompany patients during this VSED, but express moral concerns.

Keywords: ambulatory care, decision making, frequency, palliative care, professional attitude, refusal of food and liquid, surveys and questionnaire, terminal care, voluntary stopping of eating and drinking
\end{abstract}

Swiss health professionals are increasingly being confronted with patients' death wishes. According to a national survey, in $200174.5 \%$ of all nonsudden expected deaths received an end-of-life practice, rising to $82.3 \%$ in 2013: forgoing life-prolonging treatments $(49.3 \%)$, intensified alleviation of pain/symptoms (29.8\%), and physician-assisted death $(3.1 \%)$ (Schmid et al., 2016). Since then, a further end-of-life practice was established in Switzerland and included in the guideline "Management of Dying and Death" of the Swiss Academy of Medical Sciences (2018), namely, the voluntary stopping of eating and drinking (VSED). VSED has become a relevant issue in some Western societies over the last 30 years for people who wish to die independently from health and medical systems and to maintain autonomy until death (Berry \& Marcus, 2000; Cavanagh, 2014; Ganzini et al., 2003; Harvath et al., 2004; Ivanović et al., 2014; Norberg et al., 1988; Quill et al., 1997; Radbruch et al., 2019). International studies show that VSED cannot be considered an isolated phenomenon. In a survey of 307 American nurses (Ganzini et al., 2003), 33\% had already accompanied a person during VSED. In The Netherlands (Bolt et al., 2015; $N=708$ ), Germany (Hoekstra et al., 2015; $N=255$ ), and Japan (Shinjo et al., 2017; $N=571$ ), palliative care physicians and general practitioners were interviewed, and between $32 \%$ and $62 \%$ of respondents reported having accompanied at least one VSED case. In The Netherlands, VSED accounts for $0.4 \%$ to $2.1 \%$ of all deaths (Chabot \& Goedhart, 2009; Onwuteaka-Philipsen et al., 2012). Similar results were obtained in a study of long-term care institutions in Switzerland: $1.7 \%$ of all deaths in Swiss long-term care institutions were due to VSED (Stängle et al., 2019a).

\section{Background}

VSED is the free decision of a person to refuse the intake of food and fluids with the intention of ending their life prematurely (Bernat et al., 1993; Byock, 1995; Ivanović et al., 2014; Mattiasson \& Andersson, 1994; Quill et al., 1997). It is not equivalent to, for example, loss of appetite during the dying process, refusal to eat due to mental illness (e.g., dementia, anorexia), eating disorders (e.g., dysphagia), or hunger strike (Stängle et al., 2019c). According to the definition of Ivanović et al. (2014), an essential prerequisite for being able to carry out VSED is the ability of the person to wish to die (Grisso, \& Appelbaum, 1998). Voluntariness stands for the willpower of a person to make a conscious decision out of various choices, taking into account personal motives and preferences, and to act accordingly. The person also is able to appropriately resist any attempt to influence someone else's will (Zürcher, Elger, \& Trachsel, 2019). Contrary to this demand, the results of Lamore et al. (2017) show that a person's decision-making capability is significantly influenced by relatives and healthcare professionals. Relatives may try to dissuade the person who wants to die. But also the expressed willingness of relatives and professionals to accompany the person during VSED can lead to the decision 
not being reconsidered, even if doubts arise (Lamore et al, 2017; Stängle et al., 2020).

Previous surveys showed that, although people of all ages opt for the VSED, the most common age group are persons over 80 . Most (73\%) suffer from an underlying disease (including cancer, cardiovascular diseases, and neurological diseases), while about one-quarter (27\%) have no underlying disease other than old age (Bolt et al., 2015; Chabot \& Goedhart, 2009; Stängle et al., 2019b; van der Heide et al., 2012). The reasons for the decision to VSED are associated with the age and the underlying diseases of the person willing to die. Common reasons are pain, the lack of prospects for improvement, fatigue, the fear of being dependent, and the feeling of having finished life (Bolt et al., 2015; Stängle et al., 2019b). While at the beginning of the VSED the affected person retains his or her independence, the body becomes weaker and weaker over time, and delirium can also occur, resulting in a dependency on care (Fringer et al., 2018; Gärtner \& Müller, 2018; Wax et al., 2018). The person generally dies within 7 to 14 days (Ivanović et al., 2014). The involvement of professionals is therefore important from the outset in order to inform affected persons and relatives about the course of events, to ensure the provision of nursing care (e.g., oral hygiene, pressure ulcer prophylaxis) and to draw up a plan for dealing with side effects (e.g., the occurrence of delirium) (Lachman, 2015; Saladin, Schnepp \& Fringer, 2018).

About $40 \%$ of all VSED cases in Switzerland take place at home, which means that outpatient care is provided for those affected and their relatives. A guideline such as the one developed in The Netherlands (Royal Dutch Medical Association \& Dutch Nurses' Association, 2014) does not yet exist in Switzerland. In Switzerland, as in the international discussions (Alt-Epping, 2018; Fringer et al., 2018; Herzog, 2017; Jansen, 2004, 2015; Requena \& Andrade, 2018; Simon, 2018), VSED is the subject of controversial debate (Swiss Academy of Medical Sciences, 2018). Depending on the professional's attitude, VSED is considered to be suicide (Birnbacher, 2015; Gärtner \& Müller, 2018; McGee \& Miller, 2017), or as physician-assisted suicide (Quill, 2015; Requena \& Andrade, 2018), based on the similarities with the act of suicide and the individual's intention to die as well as the involvement of a professional. Another classification is passive euthanasia (Bernat et al., 1993; Simon \& Hoekstra, 2015), which emphasizes the right of a patient to discontinue life-support measures, something health professionals must accept. VSED is also described as an alternative end-of-life decision (Ganzini et al., 2003; Lachman, 2015), and because eating and drinking are not therapies or interventions, passive euthanasia doesn't apply. The only way to prevent VSED would be by force-feeding the patient, which is illegal (Wyss \& Breitschmid, 2018).
It is not yet known how VSED is classified by professionals in outpatient care in Switzerland, nor are empirical data on the occurrence of VSED in Swiss outpatient care available.

\section{Purpose and Aims}

This article reports the findings of a national study on VSED in Switzerland and clarifies its importance in outpatient care settings. We asked the following research questions: How high is the occurrence of VSED in Swiss outpatient care? What are nurses' attitudes toward VSED?

\section{Methods}

\section{Design}

We developed an evidence-based questionnaire (Stängle et al., 2019d) as part of a mixed-methods project according to our research protocol (Stängle et al., 2018). We wanted to determine the occurrence of and attitudes toward VSED among health professionals; this was used in this crosssectional study. As described in the study protocol, we interviewed three target groups: outpatient care, nursing homes, and family physicians. Results of nursing homes have already been published (Stängle et al., 2019a). This article reports on the results of outpatient care. The questionnaire was activated for online answering by the survey software Questback (EFS 10.9).

\section{Sample}

Switzerland has 2,035 outpatient care service providers (Federal Statistical Office, 2018b), which are very well organized through their respective professional associations. We contacted the management of the three largest professional associations for public, private, and freelance outpatient care to help us distribute the questionnaires to their members, all of whom assured us of their willingness. This recruitment strategy allowed a total of $79 \%(n=1,616)$ of all outpatient care services providers to be included in the study, among others:

- Spitex, a professional association for public outpatient care with 426 members (https://www.spitex.ch);

- Associations Spitex privée Suisse, a professional association for private outpatient care with 175 members (https://spitexprivee.swiss/de/);

- CURACASA, a professional association for freelance outpatient care with 1,015 members (https://www. curacasa.ch). 
Between January and August 2017, participants were invited to complete the survey. Since freelance outpatient nurses work alone, we contacted them individually. For the public and private outpatient care services, we included the head of each institution. Depending on the size of the institution, the job titles vary, including nursing director, institute director, or head nurse. We focused on the head of public and private institution as they are always involved in difficult decisions, such as accompanying a person during VSED, and we excluded registered nurses, nursing assistants, and other professions. In other words, we wished to prevent the multiple reports of the same incident by more than one nurse within the same institution. In the following, we use the term "nurse" to stand for all included participants from public, private, and freelance outpatient care services.

We sent all documents digitally to the management of the professional associations to forward to their members. They distributed the invitations to the survey via email, newsletter, and a website specifically developed by the authors for this project. In order to ensure that no more than one person from the same institution participated in the survey, we queried sociodemographic data on the profession as well as the postal code. Duplicate entries from a postal code would have led to the verification and possibly exclusion of the datasets, but this did not happen. A response rate of $20 \%$ was targeted throughout Switzerland as well as for the seven major regions, consisting of one or more cantons with an average population density of 1,041,144 people (Schuler et al., 2005).

\section{Instrument}

This study used a questionnaire (Stängle et al., 2019d) that was based on a literature search and was psychometrically tested after development (Colton \& Covert, 2007; Polit \& Beck, 2006; Polit et al., 2007) and then translated from German into French and Italian (Acquadro et al., 2012; Mahler \& Reuschenbach, 2011). We developed a questionnaire with 41 items to record the occurrence of the VSED and the experiences, attitudes, and stances about it. The answers are given on Likert scales: 1 (never), 2 (rarely), 3 (occasionally), 4 (often), and 5 (very often); or 1 (strongly disagree), 2 (disagree somewhat), 3 (neutral), 4 (agree somewhat), and 5 (strongly agree); or 1 (no), and 2 (yes). It took about 15 minutes to answer the questionnaire.

\section{Institutional Review Board}

The responsible institutional review board of the Greater Region of Eastern Switzerland (EKOS 17/083) approved this study. All participants provided written informed consent to complete the online survey.

\section{Statistical Analyses}

Descriptive analyses were performed with SPSS 25.0 (IBM, Armonk, NY, USA) and considered 95\% confidence intervals. Participants' characteristics were described with absolute and relative frequencies, means, and standard deviations.

The following approach was taken to calculate the occurrence of VSED: All participants were asked whether they had already accompanied a person during VSED; those who answered positively were additionally asked about the number of accompaniments in the past year (2016). The percentage of accompanied cases in 2016 was calculated on the basis of the number of all deaths in Switzerland in 2016, with a total of 64,649 deaths (Federal Statistical Office, 2018a) and on the basis of all persons who died at home or in an accident, with a total of 18,102 deaths (Federal Office of Public Health, 2016).

\section{Results}

\section{Description of Participants}

A total of 395 of the 1,616 participants answered the questionnaire (response rates $=35 \%$ public, $26 \%$ private, $20 \%$ freelance, and $24 \%$ total). As can be seen in Figure 1, five major regions achieved a return of more than $20 \%$, while the Lake Geneva region and Espace Mittelland only achieved a total return of $16 \%$ and $17 \%$, respectively. Associations Spitex privée Suisse has no members in Ticino. The participants' demographics are shown in Table 1.

\section{Relevance and Occurrence of VSED in Swiss Outpatient Care}

Two-thirds $(66.9 \%, n=260)$ of the participants felt that VSED is a relevant topic in outpatient care, and $63.6 \%(n=231)$ assumed that the relevance of the topic will increase in the future. Using a dichotomous scale (yes or no), most $(84.6 \%, n=334)$ participants were aware of the topic, about half $(49.1 \%, n=194)$ felt familiar with it, and $39.5 \%$ $(n=156)$ had accompanied at least one person during VSED. Of the subsample of 156 nurses with VSED experience, 143 of them provided information on the number of patients (see Table 2).

The data of the subsample of nurses with VSED experience $(n=143)$ show that, in 2016, VSED was the cause of $1.7 \%$ of all deaths at home or in an accident and accounted for $0.5 \%$ of all deaths in Switzerland. The cases were often accompanied by public outpatient care services (45.5\%), with the highest occurrence per all deaths in Eastern 


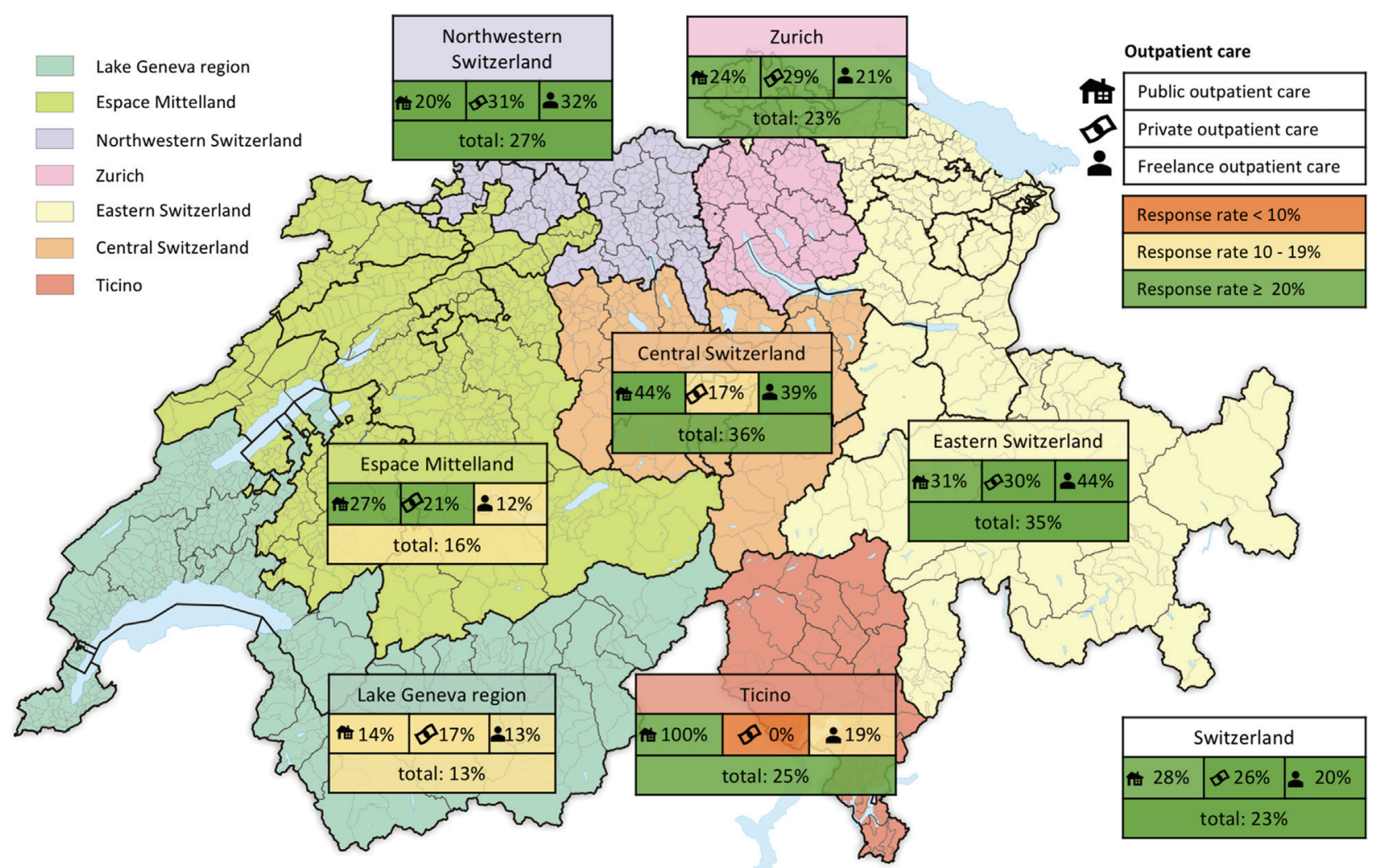

Figure 1. Response rate of public, private, and freelance outpatient care in the seven major regions of Switzerland. Source: Map from Tschubby (2019), with information on outpatient care provided by the authors.

(1.0\%) and Central (0.8\%) Switzerland, the lowest in the Lake Geneva region (0.1\%) (Table 2).

\section{Nurses' Attitudes Toward VSED}

Nurses were asked to classify VSED, to explain their attitudes toward it, and the challenges they face in accompanying a patient. For most participants (70.3\%), VSED is a "natural death." Moreover, $17.4 \%$ equated VSED with passive euthanasia in the sense of refraining from life-support measures, $6.6 \%$ considered VSED to be a person's autonomous right, while $4.9 \%$ considered it to be (physicianassisted) suicide. Lastly, $0.5 \%$ rated VSED as an expression of life fatigue and $0.3 \%$ noted it as "abandoning" a dying person.

Table 3 shows that most participants strongly agreed that VSED is compatible with their world view or religion. Half expressed no moral concerns accompanying a patient. The decision to VSED was generally accepted and respected. Almost all were convinced that people who choose VSED have a right to medical and nursing care; however, one-quarter felt that the support they receive contradicts the culture of their institution or their professional ethos. Some respondents believed that VSED would allow for dignified dying and would agree, in principle, to accompany a patient. Moreover, most could imagine VSED themselves. When asked whether they would recommend VSED as an option to patients who wish to die, a nearly equal number answered yes or no. Moreover, most attached great importance to the determination of patients' ability to judge and to reflect on their situation before deciding to stop eating and drinking. During accompaniment, many nurses felt that patients' relatives would feel burdened, and that patients' decision would be hard to accept.

\section{Expressed or Unspoken VSED}

We wanted to know whether VSED is always expressed clearly and unambiguously (verbally or nonverbally), or whether there are cases that are unspoken in which food and fluids are denied, but patients do not communicate this renunciation (neither verbally nor nonverbally). The participants $(n=392)$ noted that one-quarter $(26 \%)$ of patients expressed their intentions clearly and unambiguously, and nearly three-quarters (74\%) died as a result of not eating or drinking without making this clear (unspoken). It was also 
Table 1. Participants' characteristics

\begin{tabular}{|c|c|c|c|}
\hline & Missing & $\begin{array}{c}\text { Mean } \\
(S D) \text { range }\end{array}$ & $\begin{array}{l}\text { Absolute } \\
\text { (relative \%) } \\
\text { frequencies } \\
\end{array}$ \\
\hline Total participants & & & 395 \\
\hline \multicolumn{4}{|l|}{ Outpatient care } \\
\hline Freelance & & & $198(50.1 \%)$ \\
\hline Private & & & $46(11.6 \%)$ \\
\hline Public & & & $151(38.2 \%$ \\
\hline Age (years) & 11 & 51 (9) 25-87 & \\
\hline$<30$ years & & & $5(1.3 \%$ \\
\hline $30-39$ years & & & $29(7.6 \%$ \\
\hline $40-49$ years & & & $110(8.6 \%)$ \\
\hline $50-59$ years & & & $181(7.1 \%$ \\
\hline$\geq 60$ years & & & $59(15.4 \%)$ \\
\hline Sex & 6 & & \\
\hline Female & & & $345(8.7 \%$ \\
\hline Diverse & & & $2(0.5 \%$ \\
\hline Male & & & $42(10.8 \%)$ \\
\hline $\begin{array}{l}\text { Competence level in } \\
\text { palliative care (European } \\
\text { Credit Transfer and } \\
\text { Accumulation System) }\end{array}$ & 8 & & \\
\hline Level A1 (1-2) & & & $27(7.0 \%)$ \\
\hline Level A2 (2-3) & & & $45(11.6 \%$ \\
\hline Level B1 (5-6) & & & $55(14.2 \%)$ \\
\hline Level B2 (17-18) & & & $44(11.4 \%)$ \\
\hline Level C (60-180) & & & $12(3.1 \%)$ \\
\hline $\begin{array}{l}\text { No additional } \\
\text { qualification in palliative } \\
\text { care }\end{array}$ & & & $204(52.7 \%)$ \\
\hline Work experiences & 7 & 27 (9) 4-50 & \\
\hline$<10$ years & & & $11(2.8 \%)$ \\
\hline $10-19$ years & & & $61(15.7 \%)$ \\
\hline $20-29$ years & & & $131(3.8 \%$ \\
\hline $30-9$ years & & & $143(6.9 \%)$ \\
\hline $40-49$ years & & & $40(10.3 \%)$ \\
\hline$\geq 50$ years & & & $2(0.5 \%$ \\
\hline
\end{tabular}

of interest whether there was a connection between patients' age and whether food refusal was expressed or unspoken. The participants were asked to indicate in which age group they expect the expressed VSED and the unspoken food refusal (several answers were possible). Figure 2 shows that expressed VSED occurs at all ages but increases consistently as patients age. Further, the increase in unspoken food refusal was markedly stronger in patients aged $75+$ years.

\section{Discussion}

This cross-sectional study sought to determine the occurrence of VSED in Swiss outpatient care and what atti- tudes nurses have toward this topic. All objectives were achieved, and VSED was surveyed in outpatient care for the first time.

We found that every third participating nurse had already accompanied a VSED case, and $0.5 \%$ of all deaths in Switzerland result from VSED. The results correspond to those from nursing homes (0.7\%) (Stängle et al., 2019a), which were surveyed at the same time and with the same instrument, which means that the occurrence in Switzerland might possibly be higher. VSED occurrence is also comparable to that of The Netherlands (0.4-2.1\%) (Chabot \& Goedhart, 2009; Onwuteaka-Philipsen et al., 2012). We posit that this topic will become more relevant in the future as the Swiss population ages (Kucera \& Krummenacher, 2018), since VSED occurs more frequently as patients age (Stängle et al., 2019b).

By far the most nurses say that VSED is comparable to natural death. While the statements are in line with those of nursing homes (Stängle et al., 2019a), it presents a different picture from the current discussions in Switzerland and internationally, which are particularly concerned with the question of suicidal behavior, which was classified by only a few (4.9\%) nurses in this study. Although most participants recognized VSED as a natural death and said that they would be willing to provide care for said patients, about onequarter still expressed moral concerns. This alleged contradiction can be explained by the Ethics of Care (Held, 2006): In a caregiving relationship, when the patient becomes dependent on the caregiver, the caregiver may act emotionally and make decisions for the patient that do not match their own ideals (Held, 2006). This can also occur when accompanying a person during VSED, something that must be discussed beforehand, especially if the person who is willing to die develops delirium and later demands fluids (Gärtner \& Müller, 2018). The extent to which this has taken place among nurses could not be clarified within the framework of this research.

From a previous interview study (Stängle et al., 2019c) with relatives who have lost a loved one due to VSED, we know that there are other forms of VSED besides explicit VSED. These include the concealed form of VSED, in which patients consciously try to hide their intentions so that relatives or professionals cannot dissuade them from their VSED plans; or implicit VSED, in which people consciously stop eating without informing their surroundings. The intention would not be concealed if asked, but it turns out that especially very old people are not asked about it, as it probably was not recognized. In this study, the nurses expect a high number of unreported VSED cases and assume that, in addition to the expressed VSED cases, three more patients may be added who refuse to eat but do not openly communicate that they want to die. Especially in old age, a high proportion of people are expected to tacitly 
Table 2. Number of patients accompanied by nurses with VSED experience $(n=143)$

\begin{tabular}{|c|c|c|c|c|c|c|c|c|c|}
\hline \multirow[b]{3}{*}{ Region } & \multirow[b]{3}{*}{$n$} & \multicolumn{4}{|c|}{ Number of VSED ${ }^{1}$ cases accompanied by participants } & & & & \\
\hline & & \multicolumn{4}{|c|}{$\begin{array}{c}\text { Number of accompanied VSED cases in } 2016 \text { according } \\
\text { to the outpatient care settings }\end{array}$} & \multicolumn{4}{|c|}{ Occurrence of VSED in Switzerland } \\
\hline & & $\begin{array}{l}\text { Public } \\
\text { cases } \\
(\%)\end{array}$ & $\begin{array}{l}\text { Private } \\
\text { cases } \\
(\%)\end{array}$ & $\begin{array}{c}\text { Freelance } \\
\text { cases } \\
(\%)\end{array}$ & $\begin{array}{c}\text { Total number of } \\
\text { accompanied } \\
\text { VSED cases in } \\
2016\end{array}$ & $\begin{array}{l}\text { Deaths in } \\
2016^{2}\end{array}$ & $\begin{array}{l}\text { Occurrence } \\
\text { of VSED } \\
\text { per all } \\
\text { deaths }\end{array}$ & $\begin{array}{c}\text { Deaths at } \\
\text { home in } \\
2016^{3}\end{array}$ & $\begin{array}{l}\text { Occurrence of } \\
\text { VSED per } \\
\text { deaths at } \\
\text { home deaths }\end{array}$ \\
\hline Lake Geneva region & 12 & $2(14.3 \%)$ & $0(0 \%)$ & $12(85.7 \%)$ & 14 & 11,200 & $0.1 \%$ & 3,136 & $0.5 \%$ \\
\hline Espace Mittelland & 29 & $25(58.1 \%)$ & $7(16.3 \%)$ & $11(25.6 \%)$ & 43 & 15,924 & $0.3 \%$ & 4,459 & $1.0 \%$ \\
\hline Northwestern Switzerland & 18 & $10(23.8 \%)$ & $15(35.7 \%)$ & $17(40.5 \%)$ & 42 & 9,127 & $0.5 \%$ & 2,556 & $1.6 \%$ \\
\hline Zurich & 31 & $7(14.6 \%)$ & $12(25.0 \%)$ & $29(60.4 \%)$ & 48 & 10,652 & $0.5 \%$ & 2,983 & $1.6 \%$ \\
\hline Eastern Switzerland & 28 & $50(56.8 \%)$ & $12(13.6 \%)$ & $26(29.5 \%)$ & 88 & 9,186 & $1.0 \%$ & 2,572 & $3.4 \%$ \\
\hline Central Switzerland & 16 & $32(71.1 \%)$ & $6(13.3 \%)$ & $7(15.6 \%)$ & 45 & 5,570 & $0.8 \%$ & 1,560 & $2.9 \%$ \\
\hline Ticino & 9 & $11(50.0 \%)$ & $0(0 \%)$ & $11(50.0 \%)$ & 22 & 2,990 & $0.7 \%$ & 837 & $2.6 \%$ \\
\hline Switzerland total & 143 & 137 (45.4\%) & $52(17.2 \%)$ & $113(37.4 \%)$ & 302 & 64,649 & $0.5 \%$ & 18,102 & $1.7 \%$ \\
\hline
\end{tabular}

Note. ${ }^{1}$ VSED: voluntary stopping of eating and drinking; ${ }^{2}$ Source: Federal Statistical Office, 2018a; ${ }^{3}$ Source: Federal Office of Public Health, 2016.

\section{Expressed voluntary stopping of eating and drinking and unspoken food refusal per age group}

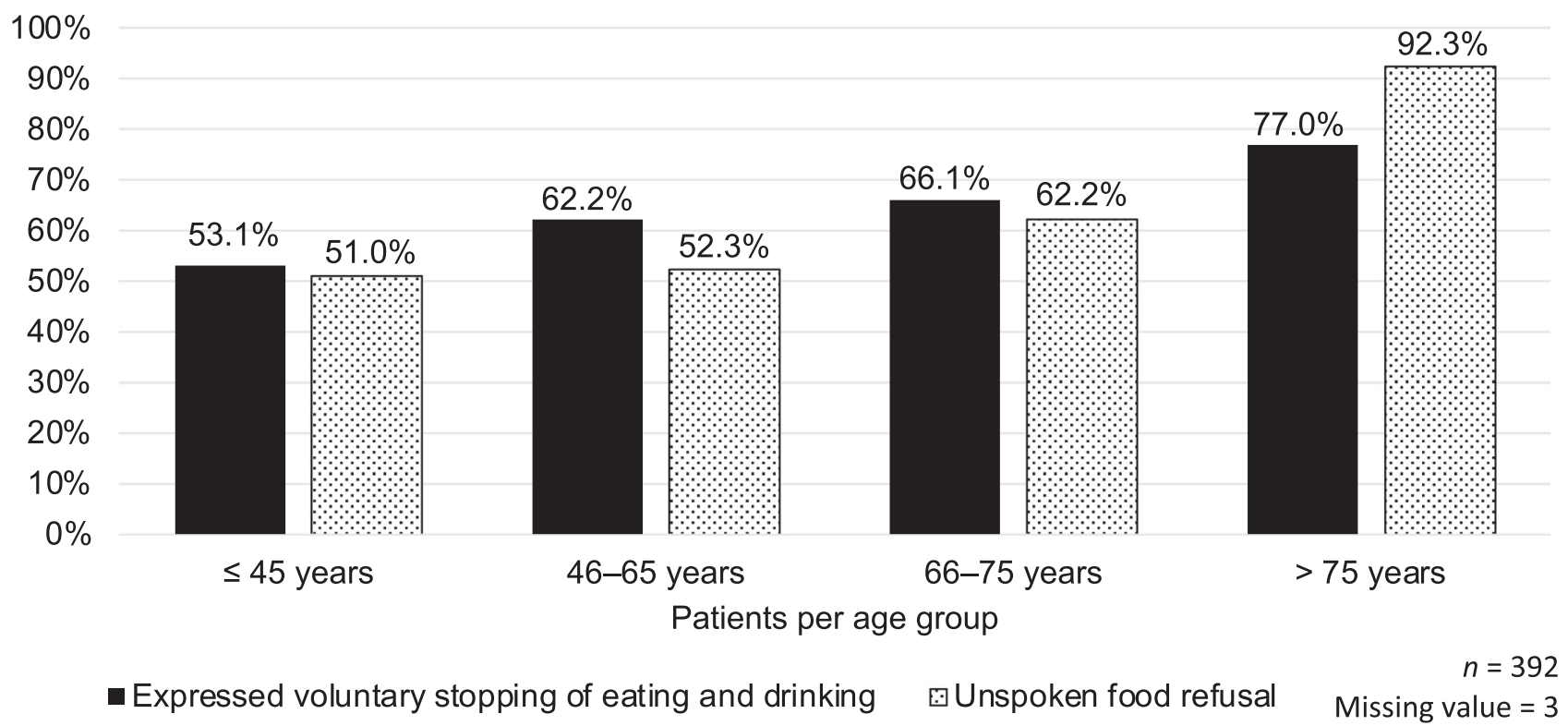

Figure 2. Expressed voluntary stopping of eating and drinking and unspoken food refusal per age group.

give up food. This may be because the outpatient care does not necessarily control the food intake and may only notice the consequences of the food shortage at a very late stage. Alternatively, it is also possible that the refusal to eat is associated with dying because of old age, so that other causes (e.g., loose teeth, pain) are not sought. Since the professionals themselves expect a high number of unspoken VSED cases, further training seems essential to ensure patient safety.

One strength of this study is that it is a large-scale national survey that, in contrast to previous studies about VSED from other countries (Bolt et al., 2015; Chabot \& Goedhart, 2009; Hoekstra et al., 2015; Shinjo et al.,
2017), it is the first to focus on outpatient care. The necessary response rate $(20 \%)$ per our study protocol (Stängle et al., 2018) and average response rate (21.5\%) of national surveys worldwide (Sax, Gilmartin, \& Bryant, 2003) were exceeded. We posit that people who have already been confronted with VSED cases are more likely to answer the questionnaire; nevertheless, it was a heterogeneous sample: $15.4 \%$ had no knowledge about the topic, and most had not accompanied a VSED patient.

Regarding the response rate per major region, the expected rates in Geneva region and Espace Mittelland were not achieved. This could result from linguistic or 
Table 3. Nurses' attitudes and professional stance

\begin{tabular}{|c|c|c|c|c|c|c|}
\hline & & $\begin{array}{l}\text { Strongly } \\
\text { disagree }\end{array}$ & $\begin{array}{c}\text { Disagree } \\
\text { somewhat }\end{array}$ & Neutral & $\begin{array}{c}\text { Agree } \\
\text { somewhat }\end{array}$ & $\begin{array}{c}\text { Strongly } \\
\text { agree }\end{array}$ \\
\hline Nurses' attitudes and professional stance & Coding & 1 & 2 & 3 & 4 & 5 \\
\hline Compatible with world view or religion & $n=393$ & $3.1 \%$ & $3.6 \%$ & $9.9 \%$ & $12.0 \%$ & $71.5 \%$ \\
\hline Have moral doubts & $n=393$ & $50.4 \%$ & $23.2 \%$ & $13.0 \%$ & $7.1 \%$ & $6.4 \%$ \\
\hline $\begin{array}{l}\text { Contradicts culture of institution/ } \\
\text { professional ethics }\end{array}$ & $n=390$ & $51.3 \%$ & $24.1 \%$ & $12.8 \%$ & $7.9 \%$ & $3.8 \%$ \\
\hline Represents a dignified death & $n=392$ & $3.3 \%$ & $5.6 \%$ & $19.4 \%$ & $28.6 \%$ & $43.1 \%$ \\
\hline Entitled to medical and nursing care & $n=392$ & $0.3 \%$ & $0.3 \%$ & $2.0 \%$ & $6.4 \%$ & $91.1 \%$ \\
\hline Accept decision & $n=394$ & $0.5 \%$ & $1.3 \%$ & $6.6 \%$ & $9.6 \%$ & $82.0 \%$ \\
\hline \multirow[t]{2}{*}{ Respect decision } & $n=394$ & - & $0.3 \%$ & $2.5 \%$ & $8.9 \%$ & $88.3 \%$ \\
\hline & & No & Yes & - & - & - \\
\hline Would personally consider it as an option & $n=390$ & $23.8 \%$ & $76.2 \%$ & - & - & - \\
\hline $\begin{array}{l}\text { Would recommend voluntary stopping of eating and } \\
\text { drinking (VSED) }\end{array}$ & $n=379$ & $51.7 \%$ & $48.3 \%$ & - & - & - \\
\hline Would care for a patient during VSED & $n=391$ & $4.9 \%$ & $95.1 \%$ & - & - & - \\
\hline Challenges during VSED & & $\begin{array}{l}\text { Strongly } \\
\text { disagree }\end{array}$ & $\begin{array}{c}\text { Disagree } \\
\text { somewhat }\end{array}$ & Neutral & $\begin{array}{c}\text { Agree } \\
\text { somewhat }\end{array}$ & $\begin{array}{l}\text { Strongly } \\
\text { agree }\end{array}$ \\
\hline Determination of patients' ability to judge the situation & $n=390$ & $3.1 \%$ & $4.1 \%$ & $14.4 \%$ & $19.7 \%$ & $58.7 \%$ \\
\hline Professionals are burdened & $n=390$ & $10.0 \%$ & $10.5 \%$ & $36.2 \%$ & $24.9 \%$ & $18.5 \%$ \\
\hline Relatives are burdened & $n=389$ & $1.3 \%$ & $3.3 \%$ & $22.4 \%$ & $31.9 \%$ & $41.0 \%$ \\
\hline Relatives have trouble accepting the decision & $n=389$ & $0.8 \%$ & $3.1 \%$ & $32.6 \%$ & $34.7 \%$ & $28.8 \%$ \\
\hline
\end{tabular}

cultural differences within Switzerland. While French is spoken in Geneva region and Espace Mittelland, and Italian is spoken in Ticino, German is the main language in the other major regions. It is assumed that, despite testing and validation, the French version of the questionnaire was not adequate. A group comparison within the major regions is recommended for further research.

\section{Conclusions}

The nurses' experience with caring for patients who embrace VSED is not uncommon in Swiss outpatient care facilities. Nurses usually classify it as a natural death and are willing to take on this new task, even if moral concerns arise. They further believe that the person has a right to medical and nursing care during VSED. In addition to the VSED cases, nurses expect a much higher proportion of patients who stop eating without this being recognized by the nurses or relatives. Especially in old age, it is assumed that there are a high number of patients who go undetected by their nurses, stop eating and die prematurely.

\section{References}

Acquadro, C., Conway, K., Giroudet, C., \& Mear, I. (2012). Linguistic validation manual for health outcome assessments. Mapi Institute.
Alt-Epping, B. (2018). Con: Der freiwillige Verzicht auf Nahrung und Flüssigkeit ist keine Form des Suizids [Con: Voluntary stopping of eating and drinking is not a form of suicide]. Zeitschrift für Palliativmedizin, 19(01), 12-15. https://doi.org/ $10.1055 / \mathrm{s}-0043-124167$

Bernat, J. L., Gert, B., \& Mogielnicki, R. P. (1993). Patient refusal of hydration and nutrition. An alternative to physician-assisted suicide or voluntary active euthanasia. Archives of Internal Medicine, 153(24), 2723-2728.

Berry, E. M., \& Marcus, E. L. (2000). Disorders of eating in the elderly. Journal of Adult Development, 7(2), 87-99. https://doi. org/10.1023/A:1009575706990

Birnbacher, D. (2015). Is voluntarily stopping eating and drinking a form of suicide? Ethik in der Medizin, 27(4), 315-324. https:// doi.org/10.1007/s00481-015-0337-9

Bolt, E. E., Hagens, M., Willems, D., \& Onwuteaka-Philipsen, B. D. (2015). Primary care patients hastening death by voluntarily stopping eating and drinking. Annals of Family Medicine, 13(5), 421-428. https://doi.org/10.1370/afm.1814

Byock, I. (1995). Patient refusal of nutrition and hydration: Walking the ever-finer line. The American Journal of Hospice \& Palliative Care, 12(2), 8-13.

Cavanagh, M. (2014). How should a Catholic hospice respond to patients who choose to voluntarily stop eating and drinking in order to hasten death? The Linacre Quarterly, 81(3), 279-285. https://doi.org/10.1179/2050854914Y.0000000025

Chabot, B. E., \& Goedhart, A. (2009). A survey of self-directed dying attended by proxies in the Dutch population. Social Science \& Medicine, 68(10), 1745-1751. https://doi.org/ 10.1016/j.socscimed.2009.03.005

Colton, D., \& Covert, R. W. (2007). Designing and constructing instruments for social research and evaluation. Jossey-Bass.

Federal Office of Public Health. (2016). Datensituation zu Palliative Care [Data situation on palliative care - evaluation of data on the place of death]. Federal Office of Public Health. 
Federal Statistical Office. (2018a). 2000 more deaths in Switzerland in 2017. Federal Statistical Office.

Federal Statistical Office. (2018b). Spitex: Synthese nach Kanton [Outpatient care services: Synthesis by canton - 2011-2017]. Federal Statistical Office.

Fringer, A., Fehn, S., Büche, D., Häuptle, C., \& Schnepp, W. (2018). Freiwilliger Verzicht auf Nahrung und Flüssigkeit (FVNF): Suizid oder natürliche Entscheidung am Lebensende [Voluntary stopping of eating and drinking (VSED): suicide or natural decision at the end of life?]. Pflegerecht, 7(2), 76-83.

Ganzini, L., Goy, E. R., Miller, L. L., Harvath, T. A., Jackson, A., \& Delorit, M. A. (2003). Nurses' experiences with hospice patients who refuse food and fluids to hasten death. The New England Journal of Medicine, 349(4), 359-365. https://doi.org/10.1056/ NEJMsa035086

Gärtner, J., \& Müller, L. (2018). Ein Fall von "Sterbefasten" wirft Fragen auf [A case of "voluntary stopping of eating and drinking” raises questions]. Schweizerische Ärztezeitung, 99(21), 675-677. https://doi.org/10.4414/saez.2018.06691

Grisso, T., \& Appelbaum, P. S. (1998). Assessing competence to consent to treatment: A guide for physicians and other health professionals. Oxford University Press.

Harvath, T. A., Miller, L. L., Goy, E., Jackson, A., Delorit, M., \& Ganzini, L. (2004). Voluntary refusal of food and fluids: attitudes of Oregon hospice nurses and social workers. International Journal of Palliative Nursing, 10(5), 236-241. https:// doi.org/10.12968/ijpn.2004.10.5.13072

Held, V. (2006). The ethics of care: Personal, political, and global. Oxford University Press on Demand.

Herzog, A. (2017). Physician-assisted suicide (PAS), physicianassisted dying (PAD), and voluntary stopping eating and drinking (VSED). Connecticut Medicine, 81(4), 243-244.

Hoekstra, N. L., Strack, M., \& Simon, A. (2015). Physicians attitudes on voluntary refusal of food and fluids to hasten death: Results of an empirical study among 255 physicians. Zeitschrift für Palliativmedizin, 16(2), 68-73. https://doi.org/ 10.1055/s-0034-1387571

Ivanović, N., Büche, D., \& Fringer, A. (2014). Voluntary stopping of eating and drinking at the end of life: A "systematic search and review" giving insight into an option of hastening death in capacitated adults at the end of life. BMC Palliative Care, 13(1), 1-8. https://doi.org/10.1186/1472-684X-13-1

Jansen, L. A. (2004). No safe harbor: The principle of complicity and the practice of voluntary stopping of eating and drinking. The Journal of Medicine and Philosophy, 29(1), 61-74. https:// doi.org/10.1076/jmep. 29.1.61.30413

Jansen, L. A. (2015). Voluntary stopping of eating and drinking (VSED), physician-assisted suicide (PAS), or neither in the last stage of life? PAS: no; VSED: it depends. Annals of Family Medicine, 13(5), 410-411. https://doi.org/10.1370/afm. 1849

Kucera, J., \& Krummenacher, A. (2018). Switzerland's population 2017. Federal Statistical Office.

Lachman, V. D. (2015). Voluntary stopping of eating and drinking: An ethical alternative to physician-assisted suicide. MEDSURG Nursing, 24(1), 56-59.

Lamore, K., Montalescot, L., \& Untas, A. (2017). Treatment decision-making in chronic diseases: What are the family members' roles, needs and attitudes? A systematic review. Patient Education and Counseling, 100(12), 2172-2181. https:// doi.org/10.1016/j.pec.2017.08.003

Mahler, C., \& Reuschenbach, B. (2011). Richtlinien zur Übersetzung von Assessmentinstrumenten [Guidelines for the translation of assessment tools]. In B. Reuschenbach \& C. Mahler (Eds.), Pflegebezogene Assessmentinstrumente (pp. 101-109). Verlag Hans Huber.
Mattiasson, A. C., \& Andersson, L. (1994). Staff attitude and experience in dealing with rational nursing home patients who refuse to eat and drink. Journal of Advanced Nursing, 20(5), 822-827.

McGee, A., \& Miller, F. G. (2017). Advice and care for patients who die by voluntarily stopping eating and drinking is not assisted suicide. BMC Medicine, 15(1), 222. https://doi.org/10.1186/ s12916-017-0994-2

Norberg, A., Bäckström, A., Athlin, E., \& Norberg, B. (1988). Food refusal amongst nursing home patients as conceptualized by nurses' aides and enrolled nurses: An interview study. Journal of Advanced Nursing, 13(4), 478-483. https://doi.org/10.1111/ j.1365-2648.1988.tb02853.x

Onwuteaka-Philipsen, B. D., Brinkman-Stoppelenburg, A. Penning, C., Jong-Krul, G. J. F., van Delden, J. J. M., \& van der Heide, A. (2012). Trends in end-of-life practices before and after the enactment of the euthanasia law in The Netherlands from 1990 to 2010: A repeated cross-sectional survey. The Lancet, 380(9845), 908-915. https://doi.org/10.1016/S01406736(12)61034-4

Polit, D. F., \& Beck, C. T. (2006). The content validity index: Are you sure you know what's being reported? Critique and recommendations. Research in Nursing \& Health, 29, 489-497. https://doi.org/10.1002/nur.20147

Polit, D. F., Beck, C. T., \& Owen, S. V. (2007). Is the CVI an acceptable indicator of content validity? Appraisal and recommendations. Research in Nursing \& Health, 30(4), 459-467. https://doi.org/10.1002/nur.20199

Quill, T.E. (2015). Voluntary stopping of eating and drinking (VSED), physician-assisted death (PAD), or neither in the last stage of life? Both should be available as a last resort. Annals of Family Medicine, 13(5), 408-409.

Quill, T. E., Lo, B., \& Brock, D. W. (1997). Palliative options of last resort: a comparison of voluntarily stopping eating and drinking, terminal sedation, physician-assisted suicide, and voluntary active euthanasia. JAMA, 278(23), 2099-2104.

Radbruch, L., Münch, U., Maier, B., Tolmein, O., Alt-Epping, B. Bausewein, C., Becker, G., Bullermann-Benend, M., Doll, A., Goudinoudis, K., Grabenhorst, U., Imbierowics, K., Klein, C. Letsch, A., Mehne, S., Müller, A., Müller-Busch, C., Nauck, F., Nehls, W., Neitzke, G., Ostgathe, C., Pfisterer, M., Riedel, A., Roser, T., Voltz, R., von Haehling, S. \& Melching, H. (2019). Positionspapier der Deutschen Gesellschaft für Palliativmedizin zum freiwilligen Verzicht auf Essen und Trinken [Position paper of the German Association for Palliative Medicine on voluntary abstinence from eating and drinking]. Deutsche Gesellschaft für Palliativmedizin e. V.

Requena, P., \& Andrade, A. D. S. (2018). Hastening death by voluntary stopping of eating and drinking. A new mode of assisted suicide? Cuadernos de Bioética, 29(97), 257-268.

Royal Dutch Medical Association.Dutch Nurses' Association. (2014). Caring for people who consciously choose not to eat and drink so as to hasten the end of life. KNMG \& V\&VN.

Saladin, N., Schnepp, W., \& Fringer, A. (2018). Voluntary stopping of eating and drinking (VSED) as an unknown challenge in a long-term care institution: An embedded single case study. BMC Nursing, 17, Article 39. https://doi.org/10.1186/s12912-018-0309-8

Sax, L. J., Gilmartin, S. K., \& Bryant, A. N. (2003). Assessing response rates and nonresponse bias in web and paper surveys. Research in Higher Education, 44(4), 409-432. https://doi.org/10.1023/a:1024232915870

Schmid, M., Zellweger, U., Bosshard, G., \& Bopp, M., Swiss Medical End-Of-Life Decisions Study Group. (2016). Medical end-of-life decisions in Switzerland 2001 and 2013: Who is involved and how does the decision-making capacity of the patient impact? Swiss Medical Weekly, 146, Article w14307. https://doi.org/10.4414/smw.2016.14307 
Schuler, M., Dessemontet, P., \& Joye, D. (2005). Eidgenössische Volkszählung 2000 - Die Raumgliederung der Schweiz [Federal Population Census 2000 - The geographical levels of Switzerland]. Federal Statistical Office.

Shinjo, T., Morita, T., Kiuchi, D., Ikenaga, M., Abo, H., Maeda, S., Tsuneto, S., \& Kizawa, Y. (2017). Japanese physicians' experiences of terminally ill patients voluntarily stopping eating and drinking: A national survey. BMJ Supportive \& Palliative Care, 9(2), 143-145. https://doi.org/10.1136/bmjspcare-2017-001426

Simon, A. (2018). Pro: Freiwilliger Verzicht auf Nahrung und Flüssigkeit als Suizid? [Pro: Voluntary stopping of eating and drinking as suicide?] Zeitschrift für Palliativmedizin, 19(1), 10-11. https://doi.org/10.1055/s-0043-124169

Simon, A., \& Hoekstra, N. L. (2015). Care for patients who choose hastened death by voluntarily stopping of eating and drinking. Deutsche Medizinische Wochenschrift, 140(14), 1100-1102. https://doi.org/10.1055/s-0041-102835

Stängle, S., Meichlinger, J., \& Fringer, A. (2020). Der freiwillige Verzicht auf Nahrung und Flüssigkeit-Ein höchst individueller Prozess für alle Beteiligten [Voluntary stopping of eating and drinking - A highly individual process for all involved]. NOVAcura, 20(5), 1-5.

Stängle, S., Schnepp, W., Büche, D., \& Fringer, A. (2019a). Longterm care nurses' attitudes and the incidence of voluntary stopping of eating and drinking: A cross-sectional study. Journal of Advanced Nursing, 76(2), 526-534. https://doi.org/ 10.1111/jan.14249

Stängle, S., Schnepp, W., Büche, D., Häuptle, C., \& Fringer, A. (2019b). Pflegewissenschaftliche Erkenntnisse über die Betroffenen, den Verlauf und der Begleitung beim freiwilligen Verzicht auf Nahrung und Flüssigkeit aus einer standardisierten schweizerischen Gesundheitsbefragung [Nursing findings from a standardised Swiss health survey on those affected, the course of the disease and the support provided when voluntarily stop eating and drinking]. Zeitschrift für medizinische Ethik, 65(3), 237-248. https://doi.org/10.14623/ zfme.2019.3.237-248

Stängle, S., Schnepp, W., \& Fringer, A. (2019c). The need to distinguish between different forms of oral nutrition refusal and different forms of voluntary stopping of eating and drinking. Palliative Care and Social Practice, 13, 1-7. https:// doi.org/10.1177/1178224219875738

Stängle, S., Schnepp, W., Mezger, M., Büche, D., \& Fringer, A. (2018). Voluntary stopping of eating and drinking in Switzerland from different points of view: Protocol for a mixed-methods study. JMIR Research Protocols, 7(12), Article e10358. https:// doi.org/10.2196/10358

Stängle, S., Schnepp, W., Mezger, M., Büche, D., \& Fringer, A. (2019d). Development of a questionnaire to determine incidence and attitudes to "voluntary stopping of eating and drinking". SAGE Open Nursing, 5, 1-7. https://doi.org/10.1177/ 2377960818812356

Swiss Academy of Medical Sciences. (2018). Management of dying and death. Swiss Academy of Medical Sciences.

Tschubby. (2019). Grossregionen der Schweiz [Major regions of Switzerland]. Wikimedia Commons van der Heide, A., Brinkman-Stoppelenburg, A., van Delden, H., \& Onwuteaka-Philipsen, B. D. (2012). Sterfgevallenonderzoek 2010: Euthanasie en andere medische beslissingen rond het levenseinde [2010 Death Survey: Euthanasia and other end-oflife medical decisions]. ZonMw.

Wax, J. W., An, A. W., Kosier, N., \& Quill, T. E. (2018). Voluntary stopping eating and drinking. Journal of the American Geriatrics Society, 66(3), 441-445. https://doi.org/10.1111/jgs.15200

Wyss, C., \& Breitschmid, P. (2018). Freiwilliger Verzicht auf Nahrung und Flüssigkeit als Form der Lebensbeendigung [Voluntary stopping of eating and drinking as a form of ending life]. Pflegerecht, 7(2), 84-89.

Zürcher, T., Elger, B., \& Trachsel, M. (2019). The notion of free will and its ethical relevance for decision-making capacity. BMC Medical Ethics, 20(1), Article 31. https://doi.org/10.1186/ s12910-019-0371-0

\section{History}

Received February 19, 2020

Accepted September 2, 2020

Published online October 30, 2020

\section{Acknowledgments}

The authors thank Lisa Pesenti of Spitexverband, Marcel Durst and Susanne Fontana-Scherer of Associations Spitex privée Suisse, and Elisabeth Engel-Müller and Joana Cattilaz of CURACASA for their support in distributing our questionnaire, as well as the participating nurses who made this research possible.

\section{Conflict of Interest}

The authors declare no conflict of interest.

\section{Editorial Note}

Acting editor was Julia Haberstroh.

\section{Funding}

This research was supported by the funding program "Research in Palliative Care" of the Swiss Academy of Medical Sciences supported by the Stanley Thomas Johnson Foundation and the Gottfried and Julia Bangerter-Rhyner Foundation. The sponsor played no role in study design, neither in data collection, analysis, or interpretation, nor in the writing or publication of this report.

\section{ORCID}

Sabrina Stängle

(D) https://orcid.org/0000-0003-1664-8824

\section{Sabrina Stängle, MSc}

Institute of Nursing

ZHAW School of Health Professions

Katharina-Sulzer-Platz 9

8400 Winterthur

Switzerland

sabrina.staengle@zhaw.ch 